\title{
Chest pain in patients with COPD: the fascia's subtle silence
}

This article was published in the following Dove Press journal:

International Journal of COPD

\author{
Bruno Bordoni' \\ Fabiola Marelli2,3 \\ Bruno Morabito ${ }^{2-4}$ \\ Roberto Castagna ${ }^{2}$ \\ 'Foundation Don Carlo Gnocchi \\ IRCCS, Department of Cardiology, \\ Institute of Hospitalization and Care \\ with Scientific Address, Milan, Italy; \\ ${ }^{2}$ CRESO, School of Osteopathic \\ Centre for Research and Studies, \\ Gorla Minore, Italy; ${ }^{3}$ CRESO, School \\ of Osteopathic Centre for Research \\ and Studies, Fano, Italy; ${ }^{4}$ Department \\ of Radiological, Oncological and \\ Anatomopathological Sciences, \\ Sapienza University of Rome, \\ Rome, Italy
}

\begin{abstract}
COPD is a progressive condition that leads to a pathological degeneration of the respiratory system. It represents one of the most important causes of mortality and morbidity in the world, and it is characterized by the presence of many associated comorbidities. Recent studies emphasize the thoracic area as one of the areas of the body concerned by the presence of pain with percentages between $22 \%$ and $54 \%$ in patients with COPD. This article analyzes the possible causes of mediastinal pain, including those less frequently taken into consideration, which concern the role of the fascial system of the mediastinum. The latter can be a source of pain especially when a chronic pathology is altering the structure of the connective tissue. We conclude that to consider the fascia in daily clinical activity may improve the therapeutic approach toward the patient.
\end{abstract}

Keywords: COPD, diaphragm, thoracic pain, fascia, muscle pain

\section{Introduction}

COPD is a worsening/degenerative condition that leads to a pathological degeneration of the respiratory system. ${ }^{1}$ It represents one of the most important causes of mortality and morbidity in the world, and it is characterized by the presence of many associated comorbidities. The World Health Organization (WHO) estimated a current mortality rate of $\sim 64$ million people per year, and in 2030 COPD will represent the third cause of mortality in the world. ${ }^{2}$ Approximately $51 \%$ of patients with COPD reportedly have at least a comorbidity, although the precise relation between COPD and these comorbidities is not entirely clear. ${ }^{1-3}$ This pathological scenario is associated with a decrease in survival rates and with more frequent hospitalization. ${ }^{3}$

There is a strong relation between the presence of pain perceived by the patient and the presence of comorbidities. ${ }^{3}$ This clinical picture worsens where the patient suffers from anxiety or depression or from other preexisting pathologies. ${ }^{3,4}$ The pain experienced by patients with COPD is stronger than the one perceived by those without a respiratory pathology or by patients with other chronic diseases. The former is only comparable to the pain observed in oncologic patients at the terminal stage. ${ }^{3,5}$ The most common causes of pain are arthritis, osteoporosis, systemic myopathy and costochondritis. Pain is generally localized in the trunk, the neck, the lumbodorsal area and the inferior limbs. ${ }^{3}$ Female patients allegedly report to experience a stronger pain. ${ }^{5}$

Recent studies emphasize the thoracic area as one of the body areas concerned by the presence of pain, with percentages between $22 \%$ and $54 \%$ in patients with COPD. ${ }^{5,6}$

This article analyzes the potential causes of mediastinal pain, that is, gastroesophageal reflux disease (GERD), a loss of elasticity of the parietal pleura, the visceral pleural receptors (VPRs) and vagal receptors, bronchial spasm or edema or a pathological
Foundation Don Carlo Gnocchi IRCCS Department of Cardiology, Institute of Hospitalization and Care with Scientific Address, S Maria Nascente, Via Capecelatro 66, Milan 20100, Italy Tel +3923496300617

Email bordonibruno@hotmail.com hereby accept the Terms. Non-commercial uses of the work are permitted without any furcher permission from Dove Medical Press Limited, provided the work is properly attributed. For permission for commercial use of this work, please see paragraphs 4.2 and 5 of our Terms (https://www.dovepress.com/terms.php). 

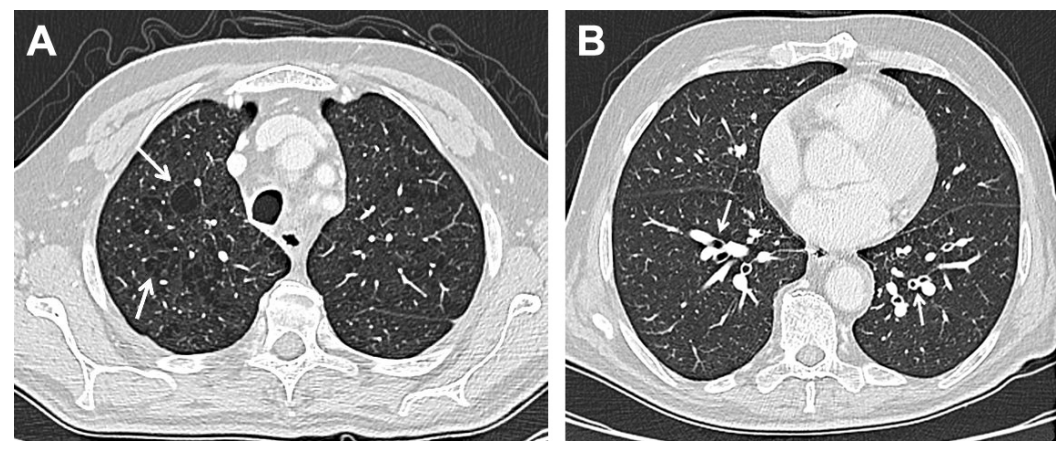

Figure I Chest CT on axial planes. Chest CT usually shows emphysema which can be centrilobular, panlobular or paraseptal; the first one is the most common type of emphysema (A), usually related to smoking status and more marked in the upper lobes; the parenchymal destruction is centered around the terminal bronchiole, representing the center of the secondary pulmonary lobule. Other findings include bronchial wall thickening (B), air trapping and narrowing of the trachea in the coronal plane.

Abbreviation: CT, computed tomography.

adaptation of the diaphragm and from its innervating system. Furthermore, this article considers the other possible sources of mediastinal pain that are related to the fascial system, which is an integral part of the somatic and visceral thoracic area: the muscular and fascial system of the rib cage, the movement and shape of the rib cage and the endothoracic and visceral fascia (Figure 1A and B).

\section{Thoracic pain: non-fascial causes GERD}

Thoracic pain can have multiple, isolated or concomitant, causes. The presence of GERD and/or hiatal hernia is a comorbidity often found in patients with COPD. This can be due to the peripheral sensitization provoked by the constant stimulation of inflammatory mediators (pepsin, bile, ATP, cytokines, hydrochloric acid and histamine), which lower the vagal and nociceptive afferential threshold. This reduction increases the permeability to cations of pain receptors, with the appearance of primary hyperalgesia. With time, other nociceptors will activate, including acid-sensing ion channels, transient receptor potential V1 and $\mathrm{P} 2 \mathrm{X}$ purinoceptors (ATP-gated ion channel). ${ }^{7}$ This symptomatological scenario can lead to phenomena such as secondary hyperalgesia and allodynia, with central sensitization caused by the persistent involvement of medullary neurons and cerebral areas, and the subsequent involvement of the psychoneuroimmune system. ${ }^{7}$ We invite the reader, if interested, to reread the article by Boeckxstaens and Rohof. ${ }^{7}$

\section{Loss of elasticity of the parietal pleura}

Thoracic pain in patients with COPD can also derive from the loss of elasticity of the parietal pleura, which is innervated by somatic fibers (intercostal nerves), and sympathetic and vagal fibers and contains nociceptors. ${ }^{8,9}$ The parietal pleura can suffer from adhesions with the visceral pleura and from scarring processes caused by a chronic inflammatory environment. In patients with COPD, the presence of inflammatory cytokines, such as transforming growth factor-beta, weakens the immune system, favoring adhesions and scars in the pleurae (parietal and visceral).$^{10}$ In the animal model, pleural adhesions determine the creation ex novo of nervous and vascular structures, suggesting that these adhesions can be a source of pain. ${ }^{11}$ The creation of pleural adhesions and scars further reduces the lung expansion in patients with COPD. ${ }^{9}$

\section{VPRs}

Another source of thoracic pain can be the visceral pleura. The VPRs are myelinated sensitive nervous fibers that derive from the spinal roots of the upper dorsal tract, which could reach the lungs through the sympathetic trunks. ${ }^{12}$ The VPRs are connected to the elastic fibers of the pulmonary parenchyma, and they are thought to be able to translate mechanical or pain stimuli in electric signals. ${ }^{8}$ If the mechanical environment is altered or overstimulated, these receptors will activate rapidly. ${ }^{13}$ The overstretching of the visceral pleura caused by a chronic overinflation of the lungs, for example, could stimulate these receptors.

\section{Vagal receptors}

There are at least seven different vagal receptors in the pulmonary area, such as high-threshold A-delta receptors and bronchial and pulmonary C-fiber receptors, which are considered as nociceptors. ${ }^{12}$ These receptors may send painful sensations because of an altered mechano-metabolic environment. The inflammation of bronchial pathways causes the production of free radicals (reactive oxygen species) $\left(\mathrm{H}_{2} \mathrm{O}_{2}\right.$, isoprostanes and nitrotyrosine residues), which can 
be found in patients with COPD and which may activate these receptors. ${ }^{13}$

\section{Bronchial spasm}

When there is a constriction, a spasm or an edema, the bronchial pathways can be a source of thoracic pain. This happens because of the activation of the abovementioned vagal receptors. ${ }^{13}$ It is important to remember that, in the presence of COPD, the mechanical bronchial tension can radically change, because of the remodeling of the inner bronchial structure caused by constant inflammation. The epithelium can generate fibroblasts, creating a pathological bronchial fibrosis. ${ }^{14}$

The intrapulmonary epithelium is innervated by a group of pulmonary neuroendocrine cells (PNECs), which can be activated by mechanical stimuli such as stretching or metabolic changes. ${ }^{12}$ We still know little about PNECs, but they could probably play a role in the sensation of pain. ${ }^{12}$

\section{A pathological adaptation of the diaphragm and from its innervating system}

The limitation of the progressive air flux in patients affected by COPD determines a pathological adaptation of the diaphragm, even though these changes are still not entirely understood. The respiratory district changes position, influencing negatively patients' tolerance for exercise. The diaphragmatic dome is lower in inhaling attitude. ${ }^{4}$ Contractile strength diminishes, with metabolic and electric alterations. The muscle thickness increases, particularly in the left side, with diminished mechanical excursion. ${ }^{4}$ This increase is probably due to the shortening of the fibers. There is a decrease in the presence of fibers of the anaerobic type (type II) and an increase in aerobic fibers (type I), a circumstance which becomes increasingly relevant as the pathology advances. The increase in the oxidative capacity, though, does not coincide with the improvement of the diaphragmatic function. The percentage of myosin drops, with an altered sarcomeric organization, further decreasing the expression of contractile strength. ${ }^{4}$ Phrenic activity is altered, probably because of the strain caused by the chronic lowering of the diaphragm, producing neuropathy. ${ }^{4}$ The diaphragm influences the perception of pain and the emotional state of the individual. This event seems to mirror the intervention of the baroreceptors. ${ }^{4}$

The baroreceptors located in the carotid body and in the area of the aortic arch, in the adventitia of the vessels, are structures that activate particularly, thanks to mechanical stimuli, for instance, when the vessels are stretched during inhalation or the flowing of blood. ${ }^{15}$ The baroreceptorial afferences are gathered by the nucleus of the solitary tract (NTS), which modulates the efferential intervention to the vagal system and the sympathetic inhibitory efference on a spinal level in the proximity of the nucleus ambiguus, of the dorsal motor nucleus and of the ventrolateral rostral area of the medulla oblongata. ${ }^{16}$ The afferences influence different areas of the central nervous system, with a general inhibitory effect. The NTS is interconnected with the reticular formation, sending information to the anterior, lateromedial and prefrontal insulae and to the anterior cingulate cortex; the thalamus, the hypothalamus and the periaqueductal gray area receive baroreceptorial signals from the NTS. ${ }^{16}$ In a healthy context, the diaphragm stimulates the baroreceptors to raise the pain threshold, favoring, with its movements, the upward venous and lymphatic return. ${ }^{4,15}$ This modulation of pressure influences the redistribution of blood, which is probably the action that determines the response of the baroreceptors and the perception of pain. ${ }^{4,15}$ Chronic and acute pain can alter the functions of the baroreceptors, just like an altered function and position of the diaphragm can negatively influence the baroreceptorial system. ${ }^{4,15}$ This creates a vicious circle, and it becomes difficult to understand the cause and the effect.

\section{The vagus nerve and the perception of pain}

The afferences of the vagus nerve are generally able to inhibit the activity of the second order of medullary neurons in the spinothalamic and spinoreticular tracts and in the trigeminal nuclei. ${ }^{4,15}$ Recent scientific evidence, however, highlights the ability to transport painful afferences from the vagus nerve, particularly visceral pain to supraspinal centers. ${ }^{4,15}$ This happens also because of the retrograde transport of inflammatory biochemical substances that travel through the nerve. The nerve itself cooperates in the creation and the maintenance of pain memory at a central level, also modulating the descending inhibitory pathway that leads back to the nociceptive medullary areas. ${ }^{4,15} \mathrm{We}$ have no precise information on these and descending mechanisms (probably involving the NTS, the parabrachial nuclei, the periaqueductal gray area, the hypothalamus, the limbic area, the magnus raphe nucleus and the locus coeruleus), but we can state that the vagal tone has an important influence on the perception of pain. ${ }^{15}$ We know that the compression of the vagus nerve can alter its function and ability to transport, just like the dysfunction of a peripheral nerve, mimicking the nerve entrapment syndrome. ${ }^{17}$ We can suppose that an anomalous tension of the diaphragm in the area of the vagal passage could induce 
the compression of the nerve, negatively affecting its antinociceptive and anti-inflammatory ability. ${ }^{17}$

\section{The phrenic nerve and the perception of pain}

The phrenic nerve is a mixed nerve, able to send efferences to the diaphragm and to receive a lot of visceral information, as well as information from the lungs, the pericardium, the vena cava, the Glisson's capsule and the peritoneal subdiaphragmatic area. ${ }^{18}$ Considering the pathological condition of the phrenic nerve in patients with COPD (neuropathy and constant nerve stretching), its anastomoses with the vagus nerve at the level of the ansa cervicalis and the relation with the NTS, we could suppose that there are phrenic, somatic and visceral nociceptive afferences. ${ }^{17-19}$ Through the spinothalamic tract and near the medullary segment $\mathrm{C} 2-\mathrm{C} 3$, the phrenic afferences overlap with visceral and trigeminal vagal afferences, precisely in the dorsal areas of the laminae I-IV. ${ }^{20,21}$ Phrenic afferences transport mechanical (proprioceptive and mechanoreceptors) and nociceptive information, not only from the diaphragm but also from the viscera that they meet on their path. ${ }^{21,22}$

The difficulty of the inspiratory muscle to bear protracted solicitations puts the respiration in a context of fatigue. ${ }^{5,23}$ Diaphragmatic fatigue in patients with COPD is more probably related to the central nervous system. ${ }^{24}$ Regardless of the cause that leads to diaphragmatic fatigue, in the presence of contractile difficulty, the phrenic afferences of type IV transport nociceptive and somatic information. ${ }^{25}$

Thoracic pain in patients with COPD can also originate from cardiac pathologies, often connected to the presence of chronic respiratory disorders. ${ }^{5}$

\section{Thoracic pain: possible fascial somatic causes}

The muscular system of the rib cage is an integral part of the fascial continuum. ${ }^{26}$ At present, there is no univocal definition of fascia, probably because of the scientific imprint of each professional who tries to create a single point of view. ${ }^{27}$ From a macro-anatomic perspective, the fascial tissue is equally distributed throughout the entire body, creating various layers at different depths and forming a three-dimensional metabolic and mechanical matrix. ${ }^{28}$ The fascial organization that covers the contractile part of the muscle can be defined as the myofascial system. ${ }^{26}$ The fascia allows the muscles to act in synergy, thanks to the fact that the fascial tissues connect all the muscular districts. ${ }^{26}$

\section{The movement and shape of the rib cage}

The movement and shape of the rib cage are altered in patients with COPD. The anteroposterior axis of the chest is some centimeters longer than in healthy patients, particularly in the lower area, taking a rounder form. ${ }^{29}$ During forced breathing, however, patients have less rib mobility than people who are not affected by chronic respiratory disorders. ${ }^{29}$ Sternocostal and costovertebral joints become stiffer, with a reduced ability to move; we can often notice a hyperkyphosis tendency of the thoracic spine in patients who are in an advanced stage of the disease. ${ }^{30}$ Costal biomechanics changes, altering the physiologic movement during inhalation. Lower lateral ribs paradoxically tend to move inwards (Hoover's sign) during inhalation..$^{31}$ A paradox movement of the lower sternum during inhalation can also occur. ${ }^{32}$ Joint stiffness and altered costal dynamics could be related to the somatic fascial system (thoracic rib muscles) (Figure 2A and B).
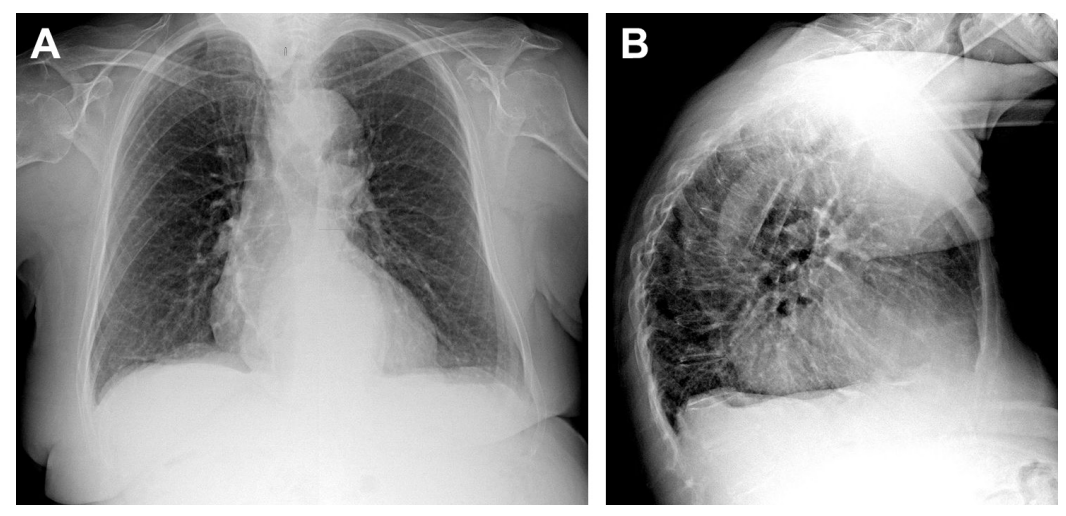

Figure 2 Chest X-ray in PA (A) and LL (B) projections. Chest X-ray has poor sensitivity to detect COPD; possible findings include prominence of the hilar vessels and decreased peripheral bronchovascular markings, flattened diaphragm due to hyperexpansion and hyperkyphosis and increased lung lucency (especially seen in the retrosternal region in LL projection) and bullae (round focal lucency over $\mathrm{I} \mathrm{cm}$ ).

Abbreviations: PA, posterior-anterior; LL, latero-lateral. 


\section{Somatic fascial system}

One of the causes of thoracic pain in patients with COPD can be related to costal muscles, which face an alteration of their physiologic length (shortening or lengthening) caused by the change of costal biomechanics, influenced in turn by lung movements. ${ }^{9,29,33}$

There are different muscles that operate on the ribs and that take part in the respiratory acts, whose behavior is not always easy to determine. Externally, the intercostal muscles are covered by the deep fascia originating from the deep cervical fascia, while, internally, they are covered by the endothoracic fascia. Laterally, these muscles form two thin layers between the intercostal spaces: one is located more externally, forming the external intercostal contractile districts, while the other is located internally, forming the internal intercostal muscles. ${ }^{34}$ Behind these muscles and near the vertebrae, the external intercostal muscles form the levator doral muscles, while the external intercostal muscles form the subcostal muscles. ${ }^{34,35}$ In the abdomen, between the sternum and the costochondral joint, the external intercostal muscles form a fibrous aponeurosis or anterior intercostal membrane, while the internal intercostal muscles form the intercostal parasternal muscles. ${ }^{34}$ The latter are covered by the triangularis sterni muscle or transversus thoracis muscle. ${ }^{36}$ The intercostal muscles that we described are innervated by the respective intercostal nerves. ${ }^{34}$

The description of the respiratory footprint of these muscles lies outside the context of this article (on this point, we refer the reader to the article by De Troyer et al). ${ }^{34}$

To understand how costal muscular districts act, it is important to remember the multiple vectors of the contractile fibers and the disposition of each rib: the muscular moment changes depending on the costal disposition (Hamberger mechanism). ${ }^{34}$ We know that the costal position changes in patients with COPD, so we can deduce that the costal contractile apparatus is in an unfavorable and non-physiologic biomechanical situation. . $^{34,37}$

The muscular respiratory disadvantage increases the risk of hospitalization. ${ }^{37}$ Costal muscles work harder, and weakness, fatigue and inflammation appear. ${ }^{37-39}$ The level of inflammatory cytokines found in costal muscles is linked to the seriousness of COPD ${ }^{40}$ Muscles suffer from hypotrophy with an increase in the amount of fat inside contractile fibers. This sarcopenia correlates with the severity of COPD. ${ }^{41}$ During intense exercise, costal muscles suffer from a reduction of blood perfusion, mirroring the inability of the circulatory system to satisfy the needs of the peripheral muscles. ${ }^{42}$

Costal muscles can be a source of chronic pain. The contractile and connective tissues have nervous terminals (group II and IV, respectively, myelinated and non-myelinated) that gather nociceptive information by mechanical, chemical and thermal stimuli. These somatic afferences travel inside intercostal nerves, bringing information to the lamina I in the medullary dorsal area, from where they will travel through the spinothalamic tract to the central nervous system, the nucleus submedius, the anterior paraventricular nucleus, the posterolateral ventral nuclei of the thalamus, the anterior cingulate cortex, the primary and secondary somatosensory cortex, the prefrontal cortex and the insular cortex. ${ }^{43-45}$

A constant stimulation of the nociceptive system will cause a plastic change in the peripheral and central nervous structures, creating the mechanism known as sensitization. ${ }^{16}$ The latter manifests itself as a lowering of the threshold of activation of spinal neurons (allodynia). In chronic conditions, the pathways of nociceptive excitation activate even when the original stimulus has ceased (hyperalgesia), often causing a similar response also by the neighboring tissues which have not been necessarily damaged (secondary hyperalgesia). ${ }^{16}$

\section{The deep fascia}

The deep fascia that covers externally the intercostal muscles and the endothoracic fascia that covers the inside of the rib cage could be sources of chronic pain. The deep fascia originates from the deep cervical fascia. ${ }^{46,47}$ Thanks to studies on other fascial areas of the human body (lower limbs, abdomen, trunk and cervical tract), we know that the fascial tissue can be innervated by spinal nerves and/or by the sympathetic system. These fibers are able to transport nociceptive afferences. ${ }^{48-50}$ In the fascia that covers intercostal muscles and in the pectoral fascia, there are nervous fibers that respond to the mechanical and nociceptive stimuli (polymodal receptors with fibers of type $\mathrm{C}$ ), which are activated by the stretching of the rib cage..$^{51}$ We know that the rib cage suffers from a biomechanical limitation and that costal muscles tend to become fibrotic. We know that the fascial tissue is in close proximity to the muscles (deep fascia and epimysium) and that it can suffer from the same non-physiologic adaptation of the contractile districts (and vice versa). ${ }^{28,50,52} \mathrm{We}$ know that the nociceptors that are in the fascia have a lower threshold of activation if the fascial tissue is less compliant (greater stiffness). ${ }^{52} \mathrm{We}$ can suppose that the deep fascia covering externally the ribs is one of the causes of thoracic pain.

\section{The endothoracic fascia}

The endothoracic fascia derives from the deep cervical fascia and delimits the internal costal area, covering the intercostal 
muscles and touching the parietal pleura. ${ }^{53-55}$ It contains lymphatic vessels, particularly in the parasternal and paravertebral areas. Especially in the latter, the endothoracic fascia comes into contact with spinal nerves and sympathetic ganglia. Vessels of the internal mammary artery can be found in the parasternal area of the fascia. ${ }^{55,56}$ The fibrosis of the different tissues that can be found in patients with COPD (muscles and pulmonary system) could be noticed in the endothoracic fascia as well, for reasons linked to anatomic and functional continuity. The fascia influences the function of the viscera it wraps around and vice versa. ${ }^{28,57}$ The fibrosis of the muscles, the fascia or the visceral tissues is similar to the wound-healing mechanism, which modifies the mechanical abilities, without necessarily altering their shape.$^{58}$ The deep fascia, like the endothoracic fascia, is made up of several layers that slide over one another (a layer defined as subserous layer of connective tissue is located between the endothoracic fascia and the parietal pleura); it is made up of structures which render it elastic, for example, elastin, proteoglycans, glycosaminoglycans and hyaluronic acid. ${ }^{58,59}$ The different layers will lose the anisotropic ability to slide if they lose water and hyaluronic acid (like in fibroses), creating greater stiffness and density of the tissue. This happens in the fascial tissue of many anatomic areas where there is chronic pain (back, neck) or in pathologies (diabetes, traumata and surgery and hormonal variations) and aging. ${ }^{58}$ The fascial tissue that loses part of its ability to slide could create adhesions to the tissues it comes into contact with, further stimulating the nociceptive fascial afferences. ${ }^{49} \mathrm{We}$ have no data on the adaptation of the endothoracic fascia in patients with COPD, but we can suppose, considering scientific elements coming from other body areas, that this deep structure could be one of the sources of the chronic pain perceived by patients.

\section{The visceral fascia}

The different organs of the mediastinum communicate with one another, thanks to visceral fascial relations. The visceral fascia that covers the organs and connects them with other organs is able to stretch and to adapt to the shape and movements of the viscera. In the presence of traumas, infections or inflammations, the visceral fascia loses its compliance and adaptability to the viscera, causing reduced movement capability and pain. ${ }^{60}$ The fascia that envelopes the lung is rich in elastic and sympathetic fibers. ${ }^{60}$ The visceral fascia that covers the lungs is closely connected to the fascial layer that envelopes the pericardium (parietal pericardium) and to the endothoracic fascia. ${ }^{61}$ In the superior mediastinum, the pulmonary visceral fascia connects the two lungs, passing behind the subclavian and the brachiocephalic arteries. This connection is called interpleural ligament or ligament of Morosow. ${ }^{62}$ In the inferior mediastinum, the esophagus (right side) and the aorta connect with a fascial structure, whose fascial boundaries attach bilaterally to the pulmonary fascia. ${ }^{62}$ The fascia between the esophagus and the descending aorta is called meso-esophageal fascia, with the presence of vagal terminals. This fascia is connected to the bronchi, to the pericardial sac (area of the left atrium) and to the trachea. ${ }^{63,64}$

Among the intrathoracic fasciae, we also have the bronchopericardial or tracheobroncho-pericardial ligament. ${ }^{65}$ It connects the terminal part of the trachea and the bronchi with the pericardium (area of the left atrium), anteriorly. ${ }^{65}$ The pretracheal fascia, deriving from the deep fascia of the neck, originates from the upper boundary of the thyroid cartilage, then covers the trachea anteriorly, touches the posterior part of the parietal pericardium (the fascia that envelopes the heart) and joins the endothoracic fascia covering the diaphragm. ${ }^{66}$ It is probably innervated by the recurrent laryngeal nerve. ${ }^{66}$ The parietal pericardium is a connective structure; it is the fascial system that covers the pericardial sac, connecting the heart and the abovementioned structures with the diaphragm, the sternum, some ribs (from the fourth to the sixth one on the left) and the thoracic vertebrae (D10-D11). ${ }^{67}$ The parietal pleura is innervated by phrenic nerves, the sympathetic system and the vagus nerve. ${ }^{67}$

We have no data on how the fascial web adapts inside the mediastinum in patients with COPD. We know that the fascia can lose its elasticity and, probably, negatively influence the viscera that it covers or with which it is in contact, altering visceral elasticity. This could lead to a change in the movement and shape of the viscera themselves, an event that, as we know, can occur in the respiratory and cardiac systems in the presence of chronic pathologies of the airways. ${ }^{68,69}$ An anomalous distention of the viscera could activate nociceptive pathways connected to the cerebellum through mossy and climbing fibers and diffuse monoaminergic and cholinergic afferents. ${ }^{70} \mathrm{~A}$-delta fibers and C-fibers, afferential nociceptive pathways, activate the previously mentioned nervous fibers through postsynaptic connections in the dorsal medullary area. Through the spino-olivo-cerebellar pathway, the nociceptive information reaches the Purkinje cells of the cerebellum. ${ }^{70}$ The cerebellum processes this nociceptive information through motor efferences. ${ }^{70}$ This scenario could be one of the reasons for the lack of motor coordination found in patients with COPD. ${ }^{71}$

The pain coming from the viscera, caused by the stiffness of the visceral fascia, could not only be one of the causes 
of perceived pain but also contribute to the patients' lack of neuromotor coordination.

The visceral fascial system could be considered as a proprioceptive organ. ${ }^{72}$ The fascia that envelopes and links the different mediastinal organs is probably a tool that the central nervous system uses to perceive the functional status of the organs, just like its position. ${ }^{27}$ If an alteration of the fascial mechanical tension (stiffness) occurs, the proprioceptive terminals will send nociceptive information, determining another cause of the mediastinal pain perceived by the patients. $^{27}$

The inflammation itself could cause nociceptive fascial afferences. ${ }^{73}$ The fascia has endocannabinoid receptors (CB1 and CB2), which, once activated, are able to eliminate pro-inflammatory cytokines. The presence of an inflammation could alter the endocannabinoid receptor response. ${ }^{73}$ Local (pulmonary) and systemic (circulatory) inflammatory environments produce multiple substances (neutrophils, macrophages, T-lymphocytes, leukotrienes B4, different interleukins and tumor necrosis factor-alpha) that are able to perpetuate this non-physiologic situation. ${ }^{74}$ Some of these substances, like macrophages and neutrophils, can synthesize neuropeptides (corticotropin-releasing factor, urocortins), which increase the sensitization of the sympathetic terminals, further lowering the threshold of the pain coming from the visceral fascia. ${ }^{75,76}$

This mechanism of inflammation that makes the fascial tissue fibrotic is always bidirectional. The lungs increase the fascial stiffness by releasing pro-inflammatory substances, just as the fascial tissue releases inflammatory substances toward the lung, probably because of a diffusion mechanism. ${ }^{74,77}$ If these scenarios should ever be confirmed by more extensive research, the visceral fascial inflammation could be proved to be another cause of thoracic pain in patients with COPD.

Several mechanisms that are important to understand the thoracic pain perceived by patients are still not entirely understood. ${ }^{6}$

\section{Conclusion}

Recent studies emphasized that between $22 \%$ and $54 \%$ of patients with COPD may suffer from thoracic pain. This pain can have different causes, for example, the presence of GERD, and nociceptive afferences by pleurae, from fibrotic or bronchial branches in spasm and from intrapulmonary epithelium. Another source of painful sensations could derive from the fascial system that covers the rib cage and/or from the mediastinal visceral fascial system. The fascial continuum remains a largely underexplored area in pathologies such as COPD, even though it would deserve more attention and more extensive research. The focus of this article was to hypothesize the possible nociceptive scenarios coming from the fascial tissue, such as the external thoracic fascia and the costal muscular complex, the endothoracic fascia and the fascial connections between the viscera of the thorax. In a local and systemic inflammatory environment such as that existing in the presence of COPD or of other mechanical and morphological alterations of the ribs and sternum, it makes sense to take into consideration the fascial system as a potential source of pain.

\section{Disclosure}

The authors report no conflicts of interest in this work.

\section{References}

1. Smith MC, Wrobel JP. Epidemiology and clinical impact of major comorbidities in patients with COPD. Int J Chron Obstruct Pulmon Dis. 2014;9:871-888.

2. Smith SM, Sonego S, Ketcheson L, Larson JL. A review of the effectiveness of psychological interventions used for anxiety and depression in chronic obstructive pulmonary disease. BMJ Open Respir Res. 2014;1(1):e000042.

3. Chen YW, Camp PG, Coxson HO, et al. Comorbidities that cause pain and the contributors to pain in individuals with chronic obstructive pulmonary disease. Arch Phys Med Rehabil. 2017;98(8):1535-1543.

4. Bordoni B, Marelli F, Morabito B, Sacconi B. Depression, anxiety and chronic pain in patients with chronic obstructive pulmonary disease: the influence of breath. Monaldi Arch Chest Dis. 2017;87(1):811.

5. Christensen VL, Holm AM, Kongerud J, et al. Occurrence, characteristics, and predictors of pain in patients with chronic obstructive pulmonary disease. Pain Manag Nurs. 2016;17(2):107-118.

6. Janssen DJ, Wouters EF, Parra YL, Stakenborg K, Franssen FM. Prevalence of thoracic pain in patients with chronic obstructive pulmonary disease and relationship with patient characteristics: a cross-sectional observational study. BMC Pulm Med. 2016;16:47.

7. Boeckxstaens GE, Rohof WO. Pathophysiology of gastroesophageal reflux disease. Gastroenterol Clin North Am. 2014;43(1):15-25.

8. Finley DJ, Rusch VW. Anatomy of the pleura. Thorac Surg Clin. 2011; 21(2):157-163.

9. Brims FJ, Davies HE, Lee YC. Respiratory chest pain: diagnosis and treatment. Med Clin North Am. 2010;94(2):217-232.

10. Thomas BJ, Kan-O K, Loveland KL, Elias JA, Bardin PG. In the shadow of fibrosis: innate immune suppression mediated by transforming growth factor- $\beta$. Am J Respir Cell Mol Biol. 2016;55(6):759-766.

11. Montes JF, García-Valero J, Ferrer J. Evidence of innervation in talcinduced pleural adhesions. Chest. 2006;130(3):702-709.

12. Adriaensen D, Brouns I, Timmermans JP. Sensory input to the central nervous system from the lungs and airways: a prominent role for purinergic signalling via P2X2/3 receptors. Auton Neurosci. 2015;191: 39-47.

13. Taylor-Clark TE, Undem BJ. Sensing pulmonary oxidative stress by lung vagal afferents. Respir Physiol Neurobiol. 2011;178(3):406-413.

14. Pain M, Bermudez $\mathrm{O}$, Lacoste $\mathrm{P}$, et al. Tissue remodelling in chronic bronchial diseases: from the epithelial to mesenchymal phenotype. Eur Respir Rev. 2014;23(131):118-130.

15. Bordoni B, Marelli F, Bordoni G. A review of analgesic and emotive breathing: a multidisciplinary approach. J Multidiscip Healthc. 2016;9: 97-102. 
16. Bordoni B, Marelli F. Failed back surgery syndrome: review and new hypotheses. J Pain Res. 2016;9:17-22.

17. Bordoni B, Bordoni G. Reflections on osteopathic fascia treatment in the peripheral nervous system. J Pain Res. 2015;8:735-740.

18. Bordoni B, Zanier E. Anatomic connections of the diaphragm: influence of respiration on the body system. J Multidiscip Healthc. 2013;6: 281-291.

19. El-Tantawi GA, Imam MH, Morsi TS. Phrenic nerve conduction abnormalities correlate with diaphragmatic descent in chronic obstructive pulmonary disease. COPD. 2015;12(5):516-524.

20. Chandler MJ, Qin C, Yuan Y, Foreman RD. Convergence of trigeminal input with visceral and phrenic inputs on primate $\mathrm{C} 1-\mathrm{C} 2$ spinothalamic tract neurons. Brain Res. 1999;829(1-2):204-208.

21. Goshgarian HG, Roubal PJ. Origin and distribution of phrenic primary afferent nerve fibers in the spinal cord of the adult rat. Exp Neurol. 1986;92(3):624-638.

22. Bałkowiec A, Kukuła K, Szulczyk P. Functional classification of afferent phrenic nerve fibres and diaphragmatic receptors in cats. $J$ Physiol. 1995;483(Pt 3):759-768.

23. Bachasson D, Wuyam B, Pepin JL, Tamisier R, Levy P, Verges S. Quadriceps and respiratory muscle fatigue following high-intensity cycling in COPD patients. PLoS One. 2013;8(12):e83432.

24. Jolley C, Luo Y, Steier J, et al. Neural respiratory drive and symptoms that limit exercise in chronic obstructive pulmonary disease. Lancet. 2015; 385 Suppl 1:S51.

25. Hill JM. Discharge of group IV phrenic afferent fibers increases during diaphragmatic fatigue. Brain Res. 2000;856(1-2):240-244.

26. Bordoni B, Marelli F. The fascial system and exercise intolerance in patients with chronic heart failure: hypothesis of osteopathic treatment. J Multidiscip Healthc. 2015;8:489-494.

27. Bordoni B, Marelli F. [Emotions in motion: myofascial interoception]. Complement Med Res. 2017;24(2):110-113. German.

28. Bordoni B, Marelli F, Morabito B, Sacconi B. The indeterminable resilience of the fascial system. $J$ Integr Med. 2017;15(5):337-343.

29. Cassart M, Gevenois PA, Estenne M. Rib cage dimensions in hyperinflated patients with severe chronic obstructive pulmonary disease. Am J Respir Crit Care Med. 1996;154(3 Pt 1):800-805.

30. Wang JS. Effect of joint mobilization and stretching on respiratory function and spinal movement in very severe COPD with thoracic kyphosis. J Phys Ther Sci. 2015;27(10):3329-3331.

31. Garcia-Pachon E, Padilla-Navas I. Frequency of Hoover's sign in stable patients with chronic obstructive pulmonary disease. Int $J$ Clin Pract. 2006;60(5):514-517.

32. Gilmartin JJ, Gibson GJ. Mechanisms of paradoxical rib cage motion in patients with chronic obstructive pulmonary disease. Am Rev Respir Dis. 1986;134(4):683-687.

33. Charalampidis C, Youroukou A, Lazaridis G, et al. Pleura space anatomy. J Thorac Dis. 2015;7(Suppl 1):S27-S32.

34. De Troyer A, Kirkwood PA, Wilson TA. Respiratory action of the intercostal muscles. Physiol Rev. 2005;85(2):717-756.

35. Kim JH, Won HS, Chung IH, Kim IB. The enigmatic subcostal muscle: anatomical study with application to spine and chest pain syndromes and avoidance of confusion on imaging. Clin Anat. 2015;28(8): $1017-1021$.

36. Jelev L, Hristov S, Ovtscharoff W. Variety of transversus thoracis muscle in relation to the internal thoracic artery: an autopsy study of 120 subjects. J Cardiothorac Surg. 2011;6:11.

37. Barreiro E, Gea J. Respiratory and limb muscle dysfunction in COPD. COPD. 2015;12(4):413-426.

38. Gea J, Casadevall C, Pascual S, Orozco-Levi M, Barreiro E. Clinical management of chronic obstructive pulmonary disease patients with muscle dysfunction. $J$ Thorac Dis. 2016;8(11):3379-3400.

39. Barreiro E, Ferrer D, Sanchez F, et al. Inflammatory cells and apoptosis in respiratory and limb muscles of patients with COPD. J Appl Physiol (1985). 2011;111(3):808-817.

40. Casadevall C, Coronell C, Ramírez-Sarmiento AL, et al. Upregulation of pro-inflammatory cytokines in the intercostal muscles of COPD patients. Eur Respir J. 2007;30(4):701-707.
41. Park MJ, Cho JM, Jeon KN, et al. Mass and fat infiltration of intercostal muscles measured by CT histogram analysis and their correlations with COPD severity. Acad Radiol. 2014;21(6):711-717.

42. Vogiatzis I, Athanasopoulos D, Habazettl H, et al. Intercostal muscle blood flow limitation during exercise in chronic obstructive pulmonary disease. Am J Respir Crit Care Med. 2010;182(9):1105-1113.

43. Conacher ID, Sudarshan G, Soni AK. Pain disaggregation theory statistical nonsense or a pointer to a paradigm for quantum nociception? Br J Anaesth. 2003;91(2):279-281.

44. Luz LL, Fernandes EC, Sivado M, Kokai E, Szucs P, Safronov BV. Monosynaptic convergence of somatic and visceral C-fiber afferents on projection and local circuit neurons in lamina I: a substrate for referred pain. Pain. 2015;156(10):2042-2051.

45. Gregory NS, Sluka KA. Anatomical and physiological factors contributing to chronic muscle pain. Curr Top Behav Neurosci. 2014;20: 327-348.

46. Stecco A, Macchi V, Masiero S, et al. Pectoral and femoral fasciae: common aspects and regional specializations. Surg Radiol Anat. 2009;31(1):35-42.

47. Lepage D, Tatu L, Loisel F, Rey PB, Obert L, Parratte B. Anatomical and computed tomography study of the eighth costochondral junction: topography for costochondral graft harvesting. Surg Radiol Anat. 2016; 38(7):809-815

48. Tesarz J, Hoheisel U, Wiedenhöfer B, Mense S. Sensory innervation of the thoracolumbar fascia in rats and humans. Neuroscience. 2011; 194:302-308

49. Wilke J, Schleip R, Klingler W, Stecco C. The lumbodorsal fascia as a potential source of low back pain: a narrative review. Biomed Res Int. 2017;2017:5349620.

50. Bordoni B, Zanier E. Clinical and symptomatological reflections: the fascial system. $J$ Multidiscip Healthc. 2014;7:401-411.

51. Stecco C, Macchi V, Porzionato A, Duparc F, De Caro R. The fascia: the forgotten structure. Ital J Anat Embryol. 2011;116(3):127-138.

52. Fede C, Albertin G, Petrelli L, et al. Hormone receptor expression in human fascial tissue. Eur J Histochem. 2016;60(4):2710.

53. Miyake N, Takeuchi H, Cho BH, Murakami G, Fujimiya M, Kitano H. Fetal anatomy of the lower cervical and upper thoracic fasciae with special reference to the prevertebral fascial structures including the suprapleural membrane. Clin Anat. 2011;24(5):607-618.

54. Natale G, Condino S, Stecco A, Soldani P, Belmonte MM, Gesi M. Is the cervical fascia an anatomical proteus? Surg Radiol Anat. 2015; 37(9):1119-1127.

55. Broglia B, Bisero E, Sclavo L, Andreozzi P. Tuberculosis of the endothoracic fascia. Pediatr Pulmonol. 2006;41(5):441-444.

56. Stopar Pintaric T, Veranic P, Hadzic A, Karmakar M, Cvetko E. Electron-microscopic imaging of endothoracic fascia in the thoracic paravertebral space in rats. Reg Anesth Pain Med. 2012;37(2):215-218.

57. Bordoni B, Zanier E. Skin, fascias, and scars: symptoms and systemic connections. J Multidiscip Healthc. 2013;7:11-24.

58. Pavan PG, Stecco A, Stern R, Stecco C. Painful connections: densification versus fibrosis of fascia. Curr Pain Headache Rep. 2014;18(8):441.

59. Karmakar MK. Thoracic paravertebral block. Anesthesiology. 2001; 95(3):771-780

60. Stecco C, Sfriso MM, Porzionato A, et al. Microscopic anatomy of the visceral fasciae. J Anat. 2017;231(1):121-128.

61. Yalcin NG, Choong CK, Eizenberg N. Anatomy and pathophysiology of the pleura and pleural space. Thorac Surg Clin. 2013;23(1): $1-10$.

62. Kato T, Akita K. Abstracts presented at the 20th Japanese Research Society of Clinical Anatomy on November 12th 2016 at National Cancer Center Hospital. Surg Radiol Anat. 2017;39(9):1029-1043.

63. Cuesta MA, Weijs TJ, Bleys RL, et al. A new concept of the anatomy of the thoracic oesophagus: the meso-oesophagus. Observational study during thoracoscopic esophagectomy. Surg Endosc. 2015;29(9): 2576-2582.

64. Weijs TJ, Goense L, van Rossum PS, et al. The peri-esophageal connective tissue layers and related compartments: visualization by histology and magnetic resonance imaging. J Anat. 2017;230(2):262-271. 
65. Nakanishi K, Goto H, Ito T. Fascial reinforcement fixing the bronchi to the heart: its anatomy and clinical significance. Surg Radiol Anat. 2017;39(12):1301-1308.

66. Cavdar S, Krause F, Dalçik H, Arifoğlu Y. The anatomy of lamina pretrachealis fasciae cervicalis. Okajimas Folia Anat Jpn. 1996;73(2-3): 105-108.

67. Rodriguez ER, Tan CD. Structure and anatomy of the human pericardium. Prog Cardiovasc Dis. 2017;59(4):327-340.

68. Neilan TG, Bakker JP, Sharma B, et al. T1 measurements for detection of expansion of the myocardial extracellular volume in chronic obstructive pulmonary disease. Can J Cardiol. 2014;30(12):1668-1675.

69. Bodduluri S, Bhatt SP, Hoffman EA, et al; COPDGene Investigators. Biomechanical CT metrics are associated with patient outcomes in COPD. Thorax. 2017;72(5):409-414.

70. Moulton EA, Schmahmann JD, Becerra L, Borsook D. The cerebellum and pain: passive integrator or active participator? Brain Res Rev. 2010; 65(1):14-27.

71. Oliveira CC, Lee AL, McGinley J, et al. Balance and falls in acute exacerbation of chronic obstructive pulmonary disease: a prospective study. COPD. 2017;14(5):518-525.
72. Stecco C, Stern R, Porzionato A, et al. Hyaluronan within fascia in the etiology of myofascial pain. Surg Radiol Anat. 2011;33(10):891-896.

73. Fede C, Albertin G, Petrelli L, et al. Expression of the endocannabinoid receptors in human fascial tissue. Eur J Histochem. 2016;60(2):2643.

74. Sinden NJ, Stockley RA. Systemic inflammation and comorbidity in COPD: a result of 'overspill' of inflammatory mediators from the lungs? Review of the evidence. Thorax. 2010;65(10):930-936.

75. Margioris AN, Dermitzaki E, Venihaki M, Tsatsani C, Gravanis A, Avgoustinaki P, Liapakis G. The multi-faceted profile of CorticotropinReleasing Factor (CRF) family of neuropeptides and of their receptors on the paracrine/local regulation of the inflammatory response. Curr Mol Pharmacol. Epub 2017 Jan 9.

76. Jänig W. Sympathetic nervous system and inflammation: a conceptual view. Auton Neurosci. 2014;182:4-14.

77. Langevin HM, Keely P, Mao J, et al. Connecting (T)issues: how research in fascia biology can impact integrative oncology. Cancer Res. 2016; 76(21):6159-6162.
International Journal of COPD

\section{Publish your work in this journal}

The International Journal of COPD is an international, peer-reviewed journal of therapeutics and pharmacology focusing on concise rapid reporting of clinical studies and reviews in COPD. Special focus is given to the pathophysiological processes underlying the disease, intervention programs, patient focused education, and self management protocols.

\section{Dovepress}

This journal is indexed on PubMed Central, MedLine and CAS. The manuscript management system is completely online and includes a very quick and fair peer-review system, which is all easy to use. Visit http://www.dovepress.com/testimonials.php to read real quotes from published authors.

Submit your manuscript here: http://www.dovepress.com/international-journal-of-chronic-obstructive-pulmonary-disease-journal 